\title{
Collective paternalism and vaccination programmes
}

Didde Boisen Andersen, Michael Bang Petersen, Søren Flinch Midtgaard, Anne-Sofie Greisen Højlund, Kasper Lippert-Rasmussen, and Viki Møller Lyngby Pedersen

Abstract: One important objection to vaccination programmes involving coercive measures such as restrictions on unvaccinated people's access to public space, or even nudging, is that they are paternalistic. We believe this objection is weaker than is often assumed. We defend this belief by: 1) introducing a novel distinction between individual and collective paternalism; 2) showing that, across a range of circumstances, vaccination programmes involve collective, not individual, paternalism; and 3) arguing that collective paternalism is not wrong for the reasons that, arguably, individual paternalism is.

Keywords: vaccine hesitancy, collective paternalism, covid-19, Feinberg, paternalism, Shiffrin, vaccination.

\section{INTRODUCTION}

Some people resist being vaccinated. Less vaccinated populations are more exposed to outbreaks, or the accelerated spread, of the relevant disease. That may put vulnerable people at risk, as it did elderly people in the case of COVID-19.[1,2] The existence of a large pool of unvaccinated people may require other disease-related measures to be put in place, and typically this is burdensome for citizens.[3] Vaccine hesitancy is also a problem, of course, for the person resisting vaccination, if the individual expected benefits of the vaccine (most importantly, the reduced risk of catching the disease) outweigh the expected costs (most importantly, the risk of side effects of the vaccine).[4] 
Given all this, it is unsurprising that the expected benefits of vaccination are often invoked to defend the state's efforts to raise vaccine uptake by means of nudging or coercion. During the present COVID-19 pandemic it has often been argued that government measures to achieve higher vaccination rates are in the public interest, or, to put this differently, 'good for everyone' - and that this is why such measures are reasonable.[5] However, many find justifications of this kind, appealing to what is good for everyone, problematic. They regard the subjection of people to coercive measures irrespective of their own views to promote what the state believes is in the citizens' best interest as paternalistic.[6] Of course, there are objections to vaccination programmes that do not appeal to paternalism: e.g., it might be complained that the sanctions imposed on those refusing vaccination (at the extreme, being shot) are too severe.[7] But we shall discuss the objection from paternalism.

We first introduce the unexplored concept of collective paternalism and distinguish it from individual paternalism. The existing literature on paternalism focuses exclusively on the latter. We argue that, in a range of cases, vaccination programmes involve collective, not individual paternalism. We explain that the applicability of the concept of collective paternalism to vaccination programmes is contingent on several factors. We indicate where these factors are present in the case of COVID-19. Finally, we argue that collective paternalism is not morally objectionable for the reasons normally adduced to explain why individual paternalism is. Accordingly, the objection to vaccination programmes from paternalism, as that objection is generally advanced, may be flawed. We conclude that the justification for state programmes of vaccination backed by coercion or nudging (as seen with COVID-19) is stronger than is commonly assumed.

\section{THE CONCEPT OF COLLECTIVE PATERNALISM}

Here is a slightly amended textbook definition of what we call individual paternalism: 
' $X$ acts paternalistically towards $Y$ by doing (omitting) $Z$ ' if, and only if:

1. ' $Z$ (or its omission) interferes with the liberty or autonomy of $Y$.

2. $X$ [does (or omits to do) Z] without the consent of $Y$.

3. $X$ [does (or omits to do) Z] ... because $X$ believes $Z$ will improve the welfare of $Y$ (where this includes preventing his welfare from diminishing), or in some way promote the interests, values, or good of $Y^{\prime} \cdot[8]^{1}$

In relation to vaccination, $X$ is the state, e.g., the relevant government committee, the government, the Cabinet, or the Prime Minister, $Y$ an individual citizen, and $Z$ is an (interventionist) attempt to ensure $Y$ undergoes vaccination. On many people's view, all three of the above conditions are satisfied: 1) the state induces people to become vaccinated under the threat of a sanction, e.g. a fine, which involves interfering with their liberty or autonomy; 2) the state acts without obtaining people's consent; and 3) the state induces people to become vaccinated because it thinks that it will improve their welfare.

Consider now the following possibility: the state implements a vaccination programme imposing sanctions on anyone who refuses vaccination. The nature of these sanctions is irrelevant for present purposes as long as the state can be said to interfere with the liberty or autonomy of citizens by penalising the option of not vaccinating. Examples of such interference would include restrictions on mobility in public space (e.g., a requirement to show vaccination certificates), fines, or even compulsory vaccination programmes such as those to be introduced in Austria and Germany from the beginning of 2022.[9] The state believes that the ranking of different outcomes from the perspective of each citizen's self-interest is the following:

\footnotetext{
${ }^{1}$ The amendment consists in omitting an 'only' between 'so' and 'because'. Acts that are motivated not only, but also, by the welfare of the agent being treated paternalistically can be morally objectionable qua being paternalistic.
} 
(Best outcome) I don't get vaccinated, but a critical mass of other people do.

(Second-best outcome) A critical mass of people, including me, get vaccinated.

(Third-best outcome) Less than the critical mass of people get vaccinated, either including or not including me. ${ }^{2}$

Suppose the state imposes a vaccination programme on its citizens without their consent - or at least without the consent of a significant, or an appropriate, proportion of them - because it thinks that its population's welfare will be higher if all are vaccinated than it would be if no one (or less than the critical mass) is vaccinated. The state knows that the vaccination programme will result in a critical mass of citizens being vaccinated. The critical mass of citizens relative to $Y$ is the number of people such that the risk of $Y$ catching the disease is so low that the costs involved in being vaccinated for any additional citizen being vaccinated outweigh the benefits. If everyone other than $Y$ is vaccinated, and vaccination effectively eliminates the risk of transmission, then the costs to $Y$ involved in being vaccinated outweigh the benefits.

While, intuitively, state imposition of a vaccination programme on its citizens to protect them from disease is paternalistic, this is in fact not so on the assumptions just stated, given Dworkin's definition of individual paternalism. This is because, as long as a critical mass of other citizens will be vaccinated, it would be better for the individual citizen - in our example, $Y$ - not to be vaccinated (see [11] on the vaccination of children for measles and pertussis).

\footnotetext{
${ }^{2}$ This ranking is consistent with the state being aware, say, that some anti-vaxxers' highestranking outcome is that no one gets vaccinated. However, the state regards such a ranking as one based on a false conception of what is in the relevant citizens' best interest (created, perhaps, by misinformation).[10] Hence, our argument applies even to anti-vaxxers.
} 
This is so even if the state imposes the vaccination programme only to promote the welfare of everyone. $^{3}$

The last point shows that the definition of paternalism offered above is too narrow. It is natural to say that the state described above acts paternalistically towards its citizens, even if it is not in the interest of citizens individually to be vaccinated when a critical mass of other citizens will be (or has already been) vaccinated. Certainly, such a state differs from one that implements a vaccination programme to protect a subset of its citizens, e.g., taxpayers, against increased healthcare costs resulting from an uncontrolled COVID-19 epidemic. A natural way to describe this difference is to say that, unlike the latter, the first kind of state acts paternalistically. It caters to the wellbeing of all of its citizens, in this way discharging one of its duties, and it does so irrespective of citizens' consent.[12]

This suggests that we need the following concept of collective paternalism:

$X$ acts paternalistically towards a set of people, $Y\left(Y_{1}, Y_{2}, \ldots Y_{n}\right)$ by doing (omitting to do) a set of acts $Z\left(Z_{1}, Z_{2}, \ldots Z_{n}\right)$ if, and only if:

$1^{*}$. For all pairs of $Z_{i}$ and $Y_{i}, Z_{i}$ (or its omission) interferes with the liberty or autonomy of $Y_{i}$.

$2^{*}$. For all pairs of $Z_{i}$ and $Y_{i}, X$ does (or omits to do) $Z_{i}$ without the consent of $Y_{i}$. 3*. $X$ does (or omits to do) $Z$... because $X$ believes that doing (or omitting to do) $Z$ will improve the welfare of all members of $Y$ (where this includes preventing their welfare from diminishing), or will in some way promote the interests, values, or good of $Y$ relative to $X$ not doing (or not omitting to do) $Z$.

\footnotetext{
${ }^{3}$ It is not true of each citizen that whatever all other citizens do, it is best for that citizen not to be vaccinated - if no other citizens are vaccinated, it is certainly best for the remaining citizen to be vaccinated. However, if each citizen thinks that a critical mass of other citizens will be vaccinated, all citizens will think that it is best for them not to be vaccinated.
} 
The crucial difference between individual and collective paternalism lies in the third condition. Unlike 3, 3* allows that $X$ can act paternalistically towards $Y$ even if $X$ believes that by doing $Z$ to $Y$, any single member of $Y, Y_{i}$ is made worse off. Intuitively, a form of paternalism is involved here. As we have defined individual and collective paternalism, it is possible for a set of actions to be collectively paternalistic and at the same time consist of individual actions none of which are individually paternalistic.

\section{WHEN VACCINATION PROGRAMMES INVOLVE COLLECTIVE PATERNALISM}

Having introduced the concept of collective paternalism, we can now ask: When does a vaccination programme involve collective rather than individual paternalism? Several factors of relevance will be mentioned here (there may be others). One is the number of people who will become vaccinated if the vaccination programme is not implemented. If what we have called a critical mass of people have already been vaccinated, or will be vaccinated shortly, in the absence of the vaccination programme, then, other things being equal, a vaccination programme is more likely to involve collective rather than individual paternalism.

A second factor is the protection the vaccination affords. If the vaccine gives the vaccinated person full protection against the disease and the disease is serious, the individual benefits from being vaccinated will be greater, other things being equal, and it will be more likely that a coercive vaccination programme will be individually paternalistic. Variance across people in terms of the protection vaccination gives them is also relevant. Some individuals may benefit less than others from being vaccinated: for example, it is less likely that a COVID-19 vaccination programme targeting children will involve collective paternalism.

A third factor relates to disease severity. If the pool of individuals who could be infected by unvaccinated individuals and are at high risk of developing a serious case of the disease 
(because, for example, they are immunocompromised) is large, then any paternalism involved is more likely to be collective than individual. Of course, these factors become even more important to the extent that transmission risk is substantially higher from unvaccinated individuals.

With this in mind, we suggest that some vaccination programmes, including programmes involving COVID-19, are best seen as collectively paternalistic. It might be objected: theorists have failed to notice the distinction between individual and collective paternalism, so surely states will overlook the distinction between 3 ) and $3^{*}$ ). More specifically, when states introduce vaccination programmes because it is better for each citizen if everyone is vaccinated than if no one is, they do so because they (sometimes falsely) believe they are promoting the welfare of each citizen. In other words, 3) requires only that the paternalistic agent is motivated by the belief that the paternalistic action promotes the welfare of the person subjected to it. Consistently with 3), that belief may be false. After all, paternalists sometimes end up making things worse for those they want to benefit.[13] Hence, vaccination programmes are likely to be objectionable because of the individual paternalism they involve if, and where, they are objectionable on grounds of paternalism at all. In response we note that even if this is so, our present point remains important. It shows that, in a range of cases, a clear-headed state vaccination programme, suitably informed by our distinction, need not involve individual paternalism.

\section{WHY COLLECTIVE PATERNALISM IS NOT WRONG FOR THE STANDARD REA- SONS}

Many theorists think that paternalism is pro tanto morally wrong, but they give different accounts of why this is so. We propose now to go over three of the main accounts, and to explain why collective paternalism does not have the wrong-making features that feature in these. Our 
remarks show, in effect, that the accounts assume individual paternalism. We begin with Seana Shiffrin's motive-based account. This is an important species of the genus of respect-based accounts of the wrongness of paternalism. One component of her definition of paternalism says:

paternalism by A toward B may be characterized as behavior (whether through action or through omission) ... (d) undertaken on the grounds that compared to B's judgment or agency with respect to those interests or other matters, A regards her judgment or agency to be (or as likely to be), in some respect, superior to B's.[13]

Shriffin's characterization has other components, but (d) plays the key role in her account of paternalism's wrongness. On her view paternalism is pro tanto wrong because it is disrespectful, and it is disrespectful because it is:

undertaken on the grounds that compared to B's judgment or agency with respect to those interests or other matters, A regards her judgment or agency to be (or as likely to be), in some respect, superior to B's... Paternalistic behavior is special because it represents a positive (although often sometimes unconscious or sometimes caring) effort by another to insert her will and have it exert control merely because of its (perhaps only alleged) superiority. As such, it directly expresses insufficient respect for the underlying valuable capacities, powers, and entitlements of the autonomous agent. Those who value equality and autonomy have special reason to resist paternalism toward competent adults.[13] 
It can be seen that this is not an objection to collective paternalism. The state does not think that, where the vaccinated person's welfare is concerned, its judgment ${ }^{4}$ vis-à-vis the vaccinated person's interests is better than the person's own judgment. Rather, it is precisely because it deems it likely that people will correctly judge it to be in their interest not to get vaccinated that it acts in a way that is collectively paternalistic. ${ }^{5}$ The problem motivating collective paternalism has to do with the payoff structure of the choice situation people are in. State officials might think that anyone - except for people who do not need to be treated paternalistically because they will imprudently (perhaps with the best intentions) get vaccinated even when it is better for them not to - whatever the quality of their judgement, will benefit from collective paternalism given the baseline of no people getting vaccinated.

Perhaps it will be said that in such cases the state regards its judgment as superior with respect to matters other than the person's interests (cf. the above quote) - for example, the individual's judgment as to whether they should be vaccinated for the collective good. In reply we would argue that states incentivize, or force, individuals to contribute to the collective good in various ways (e.g., taxation schemes), and that such substitution of judgment does not seem expressive of disrespect.

A second account of the wrongness of paternalism points to the fact that it violates people's autonomy rights. According to Joel Feinberg, paternalism involves a person's autonomy right or 'right to self-determination' being subordinated to the person's own good.[15] It is his view that:

\footnotetext{
${ }^{4}$ In what follows 'judgement' can be read as 'judgement or agency'.

${ }^{5}$ Collective paternalism does not imply that the paternalized agent does not have, or does not exercise, the moral power of developing, pursuing and revising (if need be) a conception of the good.[16]
} 
The life that a person threatens by his own rashness is after all his life; it belongs to him and to no one else. For that reason alone, he must be the one to decide-for better or worse - what is to be done with it in that private realm where the interests of others are not directly involved.[15]

Feinberg thinks that when we endorse this view, we seem to be 'logically precluded from embracing ... paternalism'.[15]

Feinberg's view might rule out individual paternalism, but it is not incompatible with collective paternalism. Collective paternalism involves a person's autonomy right being subordinated, not to his or her own good, but everyone's good. Sometimes, when I make seemingly self-regarding decisions, whether or not these actually promote my interests, the public good is clearly at stake. In such situations, what I do to my own life is a collective matter.[15] ${ }^{6}$ Hence, the objection loses its grip. Concern for individual autonomy may preclude specific sanctions introduced on the basis of an appeal to collectively paternalistic arguments, but Feinberg's objection does not preclude collective paternalism at a general level.

Consider, finally, the consequentialist angle on paternalism. For consequentialists, paternalistic interventions, however well-intended, are likely to do more harm than good. Individuals themselves, so the objection goes, know more about their own good than others do, and they are also more motivated to promote it than others are. It ought to be clear already that this objection cuts no ice against collective paternalism. Indeed, it is precisely because collective paternalists agree with the consequentialist's empirical assumptions that they endorse state interventions that are collectively paternalistic.

\footnotetext{
${ }^{6}$ Notably, collective paternalism is distinct from prevention of harm to others. This is because it aims to benefit a group, of which everyone being subjected to the paternalism is a part.
} 


\section{CONCLUSION}

We have tried to do three things. First, to introduce a novel conception of collective paternalism, distinguishing this from individual paternalism. Second, to indicate the conditions under which vaccination programmes will involve collective paternalism. Third, to show that a range of prominent accounts of what makes paternalism morally wrong do not apply to collective paternalism - in effect, they target individual paternalism. ${ }^{7}$ The article leaves open the important theoretical question of whether there is anything morally wrong with collective paternalism. It also implies that, in a range of settings, there is no paternalist objection to a vaccination programmes even if the state adopts the programme to benefit all of its citizens and does so without their consent. In outlining the concept of collective paternalism, we believe we have thrown important light on the idea that concerns about paternalism speak against nudge-based and mandatory vaccination programmes against diseases such as COVID-19.

\section{Literature:}

1 Hashim M, Alsuwaidi A, Khan G. Population risk factors for Covid-19 mortality in 93 countries. J Epidemiol Glob Health 2020;10(3):204-208.

2 Gardner W, States D, Bagley N. The coronavirus and the risks to the elderly in long-term care. J Aging Soc Policy 2020;32(4):310-315.

3 Savulescu J, Cameron J. Why lockdown of the elderly is not ageist and why levelling down equality is wrong. $J$ Med Ethics 2020;46:717-721.

4 Geiger D. Weigh the benefits of the Covid-19 vaccine against the risk for infection. DukeHealth 14 January 2021. https://www.dukehealth.org/blog/weigh-benefits-of-covid19-vaccine-against-risk-infection [Accessed December 2021].

\footnotetext{
${ }^{7}$ Of course, there could be sound, non-paternalistic objections to mandatory vaccination programmes. One might refer to the loss of trust in the state they might cause.[17]
} 
5 Kastelein N. Vaccine mandates and passports are simply a bad idea. Spectator Australia 18 September 2021. https://www.spectator.com.au/2021/09/vaccine-mandates-and-passports-are-simply-a-bad-idea/ [Accessed December 2021].

6 Cabar FR, Francisco RPV. Reflections on the need for a vaccine strategy against COVID-19 for pregnant and postpartum women. Clinics (Sao Paulo) 2021;76: e3471.

7 Kaleba N. Sanctions set for employees not complying with vaccine policy. The University Record, University of Michigan 25 October 2021. https://record.umich.edu/articles/sanctions-set-for-employees-not-complying-with-vaccine-policy/ [Accessed December 2021].

8 Dworkin G. Paternalism. In: Zalta EN, ed. The Stanford Encyclopedia of Philosophy (Fall 2020 Edition). https://plato.stanford.edu/archives/fall2020/entries/paternalism/.

9 Horowitz J, Eddy M. Austria announces Covid vaccine mandate, crossing a threshold for Europe. The New York Times 19 November 2021. https://www.nytimes.com/2021/11/19/world/europe/austria-covid-vaccine-mandate-lockdown.html [Accessed December 2021].

10 Kricorian K, Civen R, Equils O. COVID-19 vaccine hesitancy: misinformation and perceptions of vaccine safety. Hum Vaccin Immunother 2021:1-8.

11, Feikin, DR., Lezotte, DC. Hamman, RF., Salmon, DA., Chen, RT. and Hoffman, RE (2000) Individual and Community Risks of Measles and Pertussis Associated with Personal Exemptions to immunizations. JAMA 284(24): 3145-3150

12 de Marneffe P. Liberalism and Prostitution. Oxford Scholarship Online 2010:65.

13 Mill JS. On Liberty. New York: Dover Publications, Inc. 2000 [1859].

14 Shiffrin S. Paternalism, unconscionability doctrine, and accommodation. Philos Public Aff 2000;29(3):205-250,218,220.

15 Feinberg J. Harm to Self. New York: Oxford University Press 1986:22-23,57,59. 
16 Quong J. Liberalism Without Perfection. Oxford: Oxford University Press 2011.

17 Jørgensen FJ, Bor A, Petersen MB. Increased pressure leads to decreased trust among the unvaccinated: Effects of the announcement of the re-introduction of Covid passports in Denmark. PsyArxiv 2021: doi:10.31234/osf.io/j49zg. 